\title{
Identification of a Lactobacillus plantarum strain that ameliorates chronic inflammation and metabolic disorders in obese and type 2 diabetic mice
}

\author{
T. Toshimitsu, ${ }^{* 1}$ J. Mochizuki, ${ }^{*}$ S. Ikegami, $†$ and H. Itou* \\ *Lactic Acid Bacteria Research Department, and \\ †Sports Nutrition Research Department, Food Science Research Laboratories, Division of Research and Development, Meiji Co., Ltd., Odawara, \\ Kanagawa, Japan
}

\section{ABSTRACT}

In this study, we identified a strain of lactic acid bacteria (LAB) that induces high levels of IL-10 production by immune cells, and evaluated the ability of the strain to suppress chronic inflammation and ameliorate metabolic disorders in in vitro and in vivo models. Among a collection of LAB strains, Lactobacillus plantarum strain OLL2712 (OLL2712) induced the highest levels of IL-10 production in mouse-derived dendritic cells and peritoneal macrophages. The anti-inflammatory effects of this strain were evaluated using a co-culture system comprising RAW 264.7 and 3T3-L1 cells. We also administered heat-killed OLL2712 to obese and type 2 diabetic KKAy mice for 3 wk to evaluate the in vivo effects of the strain. The OLL2712 significantly decreased the production of proinflammatory cytokines in vitro. Likewise, the administration of OLL2712 significantly suppressed proinflammatory cytokine levels in both the visceral adipose tissue and the serum of KKAy mice, and reduced serum triglyceride concentrations. The strain also alleviated oxidative stress and adrenaline levels in the serum of KKAy mice. On the other hand, Lactobacillus gasseri strain MEP222804 (a moderate IL-10 inducer) did not ameliorate the systemic inflammation and hyperlipidemia in KKAy mice. Our results suggest that treatment with strong IL-10-inducing LAB has the potential to ameliorate metabolic disorders by suppressing chronic inflammation in the host animal.

Key words: dendritic cell, hyperlipidemia, inflammation, interleukin-10, Lactobacillus plantarum

\section{INTRODUCTION}

Metabolic disorders, including hyperlipidemia and hyperglycemia, have become major global health problems. Obesity is associated with hyperlipidemia, which worsens hyperglycemia by instigating peripheral insulin resistance, resulting in cerebral infarction and

Received June 6, 2015.

Accepted October 14, 2015.

${ }^{1}$ Corresponding author: takayuki.toshimitsu@meiji.com. cardiovascular diseases (Dandona et al., 2005). Obesity is currently defined as a low-grade chronic inflammatory disease that is associated with elevated levels of circulating proinflammatory cytokines (Shoelson et al., 2007). This inflammation impairs glucose and lipid metabolism and causes insulin resistance in adipose tissue as well as muscle and liver tissues (Fantuzzi, 2005). It was also reported that macrophage infiltration contributes to chronic inflammation in visceral adipose tissue by mediating increased production of proinflammatory cytokines and decreased production of adiponectin, a key regulator of insulin sensitivity and tissue inflammation, in adipose cells (Weisberg et al., 2003; Xu et al., 2003). This interaction between macrophages and adipose cells is considered to be the primary cause of the induced chronic inflammation in visceral adipose tissue. Thus, the alleviation of low-grade chronic inflammation in these tissues, by suppressing macrophage infiltration, may ameliorate or prevent metabolic disorders.

Interleukin-10, an anti-inflammatory cytokine secreted primarily by dendritic cells and macrophages (Howard and O'Garra, 1992), can inhibit the production of the proinflammatory cytokines that induce chronic inflammation in visceral adipose tissue (Lumeng et al., 2007). A previous study reported that human metabolic disorders were associated with a low capacity of the immune cells to produce IL-10 (van Exel et al., 2002). The inhibition of endogenous IL-10 promoted an increased expression of inflammatory cytokines such as tumor necrosis factor $\alpha$ (TNF- $\alpha)$ and IL-6, a worsening of insulin signaling, and the activation of gluconeogenic and lipogenic pathways (Cintra et al., 2008). Conversely, the addition of IL-10 protected adipocytes from $T N F-\alpha$-induced insulin resistance, and enhanced insulin-stimulated glucose uptake in adipocytes (Lumeng et al., 2007). These findings indicate that IL-10 plays an important role in the alleviation of chronic inflammation, and that modulation of IL-10 production may therefore prevent metabolic disorders.

Lactic acid bacteria (LAB) have been reported to stimulate immune activity or ameliorate immunerelated diseases by affecting immune cells within the intestinal tract (Parvez et al., 2006). Furthermore, recent 
studies indicate that the immunomodulatory activities of LAB have positive effects on obesity and insulin resistance (Takemura et al., 2010; Naito et al., 2011). These reports therefore suggest that the presence of certain LAB may ameliorate or prevent metabolic disorders by stimulating immune cells in the intestinal tract. Interestingly, the beneficial effects of LAB are considered to be strain- rather than species-dependent (Sashihara et al., 2006). However, to the best of our knowledge, no studies have used in vitro methods to select for LAB strains that exhibit optimal immunomodulatory activity for the improvement of metabolic disorders and then evaluated the efficacy of the selected strains in ameliorating metabolic disorders using in vivo models.

In the present study, we hypothesized that LAB strains that induce high levels of IL-10 production have the possibility to prevent metabolic disorders via the alleviation of chronic inflammation. To address this possibility, we screened a panel of LAB and identified the strain that mediated the highest level of IL10 production in bone marrow-derived dendritic cells (BMDC) and peritoneal macrophages (PM). We then carried out in vitro and in vivo analyses to investigate the potential of the selected strain to suppress chronic inflammation and ameliorate metabolic disorders.

\section{MATERIALS AND METHODS}

\section{Bacterial Strains and Growth Conditions}

Lactobacilli were isolated from the feces of young Japanese female volunteers, using Lactobacillus Selection Agar (Becton Dickinson, Franklin Lakes, NJ). Several strains of homolactic-fermenting lactobacilli were selected from a total of 273 isolates, for their gastric and bile acid resistance capabilities. Lactobacillus gasseri strain JCM $1131^{\mathrm{T}}$ and Lactobacillus plantarum strain $\mathrm{JCM} 1149^{\mathrm{T}}$ were purchased from the Japanese Culture Collection (Riken, Wako, Japan). All microorganisms were grown in de Man, Rogosa, and Sharpe broth (Becton Dickinson) at $37^{\circ} \mathrm{C}$ for $18 \mathrm{~h}$. After fermentation, the cells were harvested in a refrigerated centrifuge $\left(8,000 \times g, 15 \mathrm{~min}, 4^{\circ} \mathrm{C}\right)$ and washed twice with a saline solution, followed by one wash with water. The cells were resuspended in distilled water, heat-killed by incubation at $75^{\circ} \mathrm{C}$ for $60 \mathrm{~min}$, and lyophilized. The lyophilized cells were resuspended in PBS ( $\mathrm{pH} 7.2)$ at an adequate concentration and used for the in vitro and in vivo assays.

\section{Handling of Mice Used in This Study}

Eight-week-old specific-pathogen-free male BALB/c mice were purchased from Japan SLC (Shizuoka, Ja- pan) and used for the preparation of immune cells. Five-week-old specific-pathogen-free male KKAy mice and age-matched C57BL/6J mice were purchased from CLEA Japan (Shizuoka, Japan) and used for the in vivo studies. For these studies, all mice were housed individually and were acclimatized with a purified diet (AIN-93M; Oriental Yeast Co. Ltd., Tokyo, Japan) for a week before starting the experiment. The KKAy mice were divided into 3 groups: mice administered distilled water, L. plantarum OLL2712 (OLL2712), or L. gasseri MEP222804 (MEP222804; $\mathrm{n}=5$ or 6 per group). On each day, the mice were intragastrically administered $0.5 \mathrm{~mL}$ of either distilled water or distilled water containing lyophilized powder of heat-killed LAB (4 mg/mouse). After $3 \mathrm{wk}$ of feeding, the mice were subjected to fasting for $4 \mathrm{~h}$ and then anesthetized by isoflurane inhalation; then, whole blood was drawn from the axillary artery. The serum was separated from the blood samples and used to measure the levels of lipids and cytokines. The epididymal white adipose tissue was removed from each mouse and stored in RNAlater solution (Ambion, Austin, TX). All study protocols were approved by the Animal Care Committee of the Food Science Research Laboratories (approval number: 2013_3871_0093), and animals were maintained in accordance with the guidelines for the care and use of laboratory animals of Meiji Co. Ltd.

\section{Preparation of Immune Cells}

The BMDC were generated from cells collected from the tibia and femur of the BALB/c mice, as previously described (Kawashima et al., 2013). After red blood cell lysis and depletion of cells expressing CD4, CD8, and MHC II (I-A/I-E) by using magnetic beads (Miltenyi Biotec, Bergisch Gladbach, Germany) and Auto MACS (Miltenyi Biotec) for excluding $\mathrm{T}$ cells and antigenpresenting cells, the cells were cultured in RPMI 1640 medium (Invitrogen, Carlsbad, CA) containing 10\% fetal bovine serum (FBS) and 10\% granulocyte macrophage colony-stimulating factor. On d 8 , nonadherent and loosely adherent cells were harvested. The PM were harvested $3 \mathrm{~d}$ after intraperitoneal injection of 2 $\mathrm{mL}$ of $4 \%$ thioglycolate broth (Becton Dickinson) into the BALB/c mice. The cells were washed with PBS and cultured in RPMI 1640 medium.

\section{Co-Culture of Adipocytes and Macrophages}

The 3T3-L1 and RAW 264.7 cells were used for the co-culture experiments. The 3T3-L1 cells (American Type Culture Collection, Rockville, MD) were used as a model of mouse adipose cells, and were cultured in Dulbecco's modified Eagle's medium (DMEM; Sigma 
Aldrich, St. Louis, MO) containing $25 \mathrm{mmol} / \mathrm{L}$ glucose and $10 \%$ calf serum and maintained in a water-jacketed incubator set to $37^{\circ} \mathrm{C}$ and $5 \%$ carbon dioxide. All reagents used to induce cell differentiation were purchased from Takara (Kyoto, Japan) and the 3T3-L1 cells were differentiated into mature adipocytes according to the manufacturer's instructions, as previously described (Suganami et al., 2005). Briefly, confluent cells were induced to differentiate by incubating for $48 \mathrm{~h}$ with differentiation medium (DMEM supplemented with $10 \mu \mathrm{g} / \mathrm{mL}$ of insulin, $2.5 \mu \mathrm{mol} / \mathrm{L}$ of dexamethasone, $0.5 \mathrm{mmol} / \mathrm{L}$ of 3 -isobutyl-1-methylxanthine, and $10 \%$ FBS). Cells were then maintained in DMEM containing $10 \mu \mathrm{g} / \mathrm{mL}$ of insulin solution and 10\% FBS for 48 h. After $6 \mathrm{~d}$ of further incubation, the cells were used for the co-culture experiments. The RAW 264.7 cells (American Type Culture Collection) were used as a model of mouse macrophages. The cells were cultured in RPMI 1640 medium containing 10\% FBS and were maintained under the same conditions as used for the 3T3-L1 cells. Co-culture was performed using Transwell plates (Corning, Acton, MA) with $0.4-\mu \mathrm{m}$ pore membrane inserts to separate the upper and lower chambers. The differentiated 3T3-L1 cells were cultured in the lower chambers, whereas $1 \times 10^{6}$ RAW 264.7 cells were cultured in the upper chamber. The RAW 264.7 cells were then treated with heat-killed OLL2712 or MEP222804 cells (10 ng/mL) for $48 \mathrm{~h}$.

\section{Cytokine Analyses}

The conditioned medium was removed from the cell cultures at designated times and centrifuged at $800 \times g$ for $5 \mathrm{~min}$ at $4^{\circ} \mathrm{C}$. Cytokine concentrations were assayed using ELISA kits (BD Biosciences, San Diego, CA). The adiponectin concentrations were measured using the AssayMax Mouse Adiponectin ELISA Kit (Assaypro, St. Charles, MO) according to the manufacturer's instructions.

\section{Measurement of Blood Glucose, Lipid, and Adipocytokine Levels}

Blood glucose concentrations were measured using the Breeze 2 blood glucose monitoring system (Bayer Healthcare, Whippany, NJ). Serum concentrations of triglycerides and total cholesterol were measured using the Fuji Dri-Chem analyzer and special slides (TCHOP III slide and TG-P III slide; Fujifilm, Tokyo, Japan). Serum levels of proinflammatory cytokines were measured using a multiplex mouse cytokine bead array system (Bio-Rad, Hercules, CA). Serum adiponectin concentrations were measured using the Adiponectin (Mouse) Total, HMW ELISA Kit (ALPCO, Salem,
$\mathrm{NH})$. Serum leptin concentrations were measured using the AssayMax Mouse Leptin ELISA Kit (Assaypro). Serum adrenaline and noradrenaline concentrations were measured using the 3-CAT Research ELISA Kit (LDN, Nordhorn, Germany).

\section{Measurement of Serum Oxidative Stress}

Oxidative stress was assessed by measuring the serum levels of reactive oxygen metabolites (d-ROM) using the Free Radical Elective Evaluator (FREE Carpe Diem; Wismer LL Co., Tokyo, Japan). For the d-ROM test, serum samples were dissolved in an acidic buffer. The transition metal ions that are liberated from the serum proteins in the acidic medium react with hydroperoxides, resulting in a conversion to proxy and peroxyl radicals. These radicals are able to oxidize $N, N$-diethyl-para-phenylenediamine, which can be detected spectrophotometrically. Measurements obtained in the d-ROM tests are presented as Carr units. Serum concentrations of 8-hydroxy-2'-deoxyguanosine (8-OHdG), a marker of oxidative DNA damage, were measured using the Highly Sensitive $8-\mathrm{OHdG}$ Check ELISA Kit (Japan Institute for the Control of Aging, Tokyo, Japan).

\section{Isolation of RNA and Real-Time PCR Analysis}

Total RNA was prepared from frozen mouse tissue samples and from 3T3-L1 cells using extraction kits designed for adipose tissues (Qiagen, Valencia, CA) and the TRIzol reagent (Invitrogen), respectively, following the manufacturers' protocols. The RNA was quantified and assessed for purity using a NanoDrop 1000 spectrophotometer (Thermo Scientific, Wilmington, DE). Complementary DNA was synthesized from $1 \mu \mathrm{g}$ of total RNA using the PrimeScript RT Master Mix (Takara), and real-time PCR was performed using a 7300 Real-Time PCR system (Applied Biosystems, Foster City, CA) and SYBR Premix Ex Taq (Takara). The primer sequences used are listed in Table 1 . The mRNA expression levels were assessed by the comparative $\mathrm{C}_{\mathrm{T}}$ (cycle threshold) method, correcting for the amplification efficiency of the primers. The data were normalized to the values of $\beta$-actin, and results were expressed as fold changes to threshold cycle values relative to controls.

\section{Statistical Analyses}

Results are presented as the mean \pm standard error. Statistical evaluation was performed using StatView software (SAS, Cary, NC). Statistical differences were 
analyzed using Dunnett's test or Steel's test. Statistical significance was considered at $P<0.05$.

\section{RESULTS}

\section{Identification of LAB that Induce High Levels of IL-10 Production in Immune Cells}

We first evaluated the effects of several LAB species on the production of the anti-inflammatory cytokine IL-10 in BMDC and PM. These analyses indicated that heat-killed samples of various $L$. plantarum and $L$. gasseri strains induced markedly higher levels of IL-10 production than the other lactobacilli species tested, including Lactobacillus casei, Lactobacillus brevis, Lactobacillus crispatus, and Lactobacillus amylovorus (data not shown). For this reason, we chose to focus on assessing the IL-10-inducing activity of a panel of $L$. plantarum and L. gasseri strains. As depicted in Figure 1, OLL2712 induced the highest levels of IL-10 production in both BMDC and PM. Among the L. gasseri strains, the moderate IL-10 inducer strain MEP222804 was selected as a representative LAB strain to contrast with OLL2712 when assessing the potential of LAB to ameliorate metabolic disorders in subsequent experiments.

\section{Anti-Inflammatory Activity of OLL2712 on Co-Cultured RAW 264.7 and 3T3-L1 cells}

To evaluate the effects of the selected strains on inflammation in adipocytes, we generated a co-culture system composed of RAW 264.7 and 3T3-L1 cells using Transwell plates. For these experiments, differentiated 3T3-L1 cells were cultured in the bottom wells, whereas the RAW 264.7 cells were cultured in the upper chambers. Heat-killed OLL2712 or MEP222804 cells were then added to the upper chambers containing the macrophage cell line. The concentrations of adiponectin were significantly decreased, whereas those of TNF- $\alpha$, IL-6, and monocyte chemotactic protein-1 (MCP-1) were significantly increased in the supernatants of the co-cultured 3T3-L1 cells (RAW+) compared with the levels from a monoculture of 3T3-L1 cells (RAW-), indicating that the presence of the macrophages induced inflammatory conditions in the adipose cells (Figure $2 \mathrm{~A}$ ). However, when the RAW 264.7 cells were treated with OLL2712, a significant reduction in the production of proinflammatory cytokines was noted, as well as a trend toward decreased adiponectin production $(P$ $=0.06)$ in the 3T3-L1 cells. Conversely, treatment with MEP222804 only affected the levels of TNF- $\alpha$ production (Figure 2A).

To assess whether the reduced levels of proinflammatory cytokines were due to LAB-mediated inhibition of cytokine production or secretion, we quantified the mRNA expression levels of the cytokines in the co-cultured 3T3-L1 cells. Real-time PCR analyses demonstrated that the expression levels of these cytokines were consistent with the extracellular concentrations detected by ELISA (data not shown). Furthermore, we measured the mRNA levels of the antioxidant enzyme CuZn-superoxide dismutase (SOD) in 3T3-L1 cells. Whereas treatment with OLL2712 significantly enhanced the mRNA expression of CuZn-SOD, the addition of MEP222804 had no significant effect on the expression of this enzyme (Figure 2B). These results indicate that exposure to OLL2712 affects the transcript levels of both proinflammatory (TNF- $\alpha$, IL-6, and MCP-1) and anti-inflammatory (adiponectin and CuZn-SOD) molecules in 3T3-L1 cells.

\section{Effects of OLL2712 Administration in KKAy Mice}

To address the in vivo effects of LAB on metabolic disorders, KKAy mice, which are a model of obesity and type 2 diabetes (T2D), were treated with OLL2712 or MEP222804. For these experiments, untreated C57BL/6J mice were used as the normal group and untreated KKAy mice were used as the control group. The KKAy test group were fed heat-killed OLL2712 or MEP222804 cells for 3 wk. Whereas mice treated with OLL2712 exhibited a significant reduction in fasting serum triglyceride concentrations compared

Table 1. Primers used for real-time PCR

\begin{tabular}{lll}
\hline Gene & Forward primer & Reverse primer \\
\hline$I L-6$ & $5^{\prime}$-gatgctaccaaactggatataatc-3' & $5^{\prime}$-ggtccttagccactccttctgtg-3' \\
$T N F-\alpha$ & $5^{\prime}$-aaatggcctccctctcatca-3' & $5^{\prime}$-agatagcaaatcggctgacg-3' \\
$M C P-1$ & $5^{\prime}$-aagagaatcaccagcagcaggt-3' & $5^{\prime}$-ttctggacccattccttattgg-3' \\
$I L-1 \beta$ & $5^{\prime}$-gtggaccttccaggatgagg-3' & $5^{\prime}$-cggagctgtagtgcagttg-3' \\
Adiponectin & $5^{\prime}$-gatggcagagatggcactc-3' & $5^{\prime}$-cttgccagtgctgccgtcat-3' \\
$C u Z n$ - $S O D$ & $5^{\prime}$-'cagcatgggttccacgtcca-3' & $5^{\prime}$-cacattggccacaccgtct-3' \\
$F 4 / 80$ & $5^{\prime}$-ctttggctatgggcttccagtc-3' & $5^{\prime}$-gcaaggaggacagagtttatcgtg-3' \\
$C D 68$ & $5^{\prime}$-cttcccacaggcagcacag-3' & $5^{\prime}$-aatgatgagaggcagcaagagg-3' \\
$\beta$-actin & $5^{\prime}$-gattactgctctggctcctagc-3' & $5^{\prime}$-gactcatcgtactcctgcttgc-3' \\
\hline
\end{tabular}


A

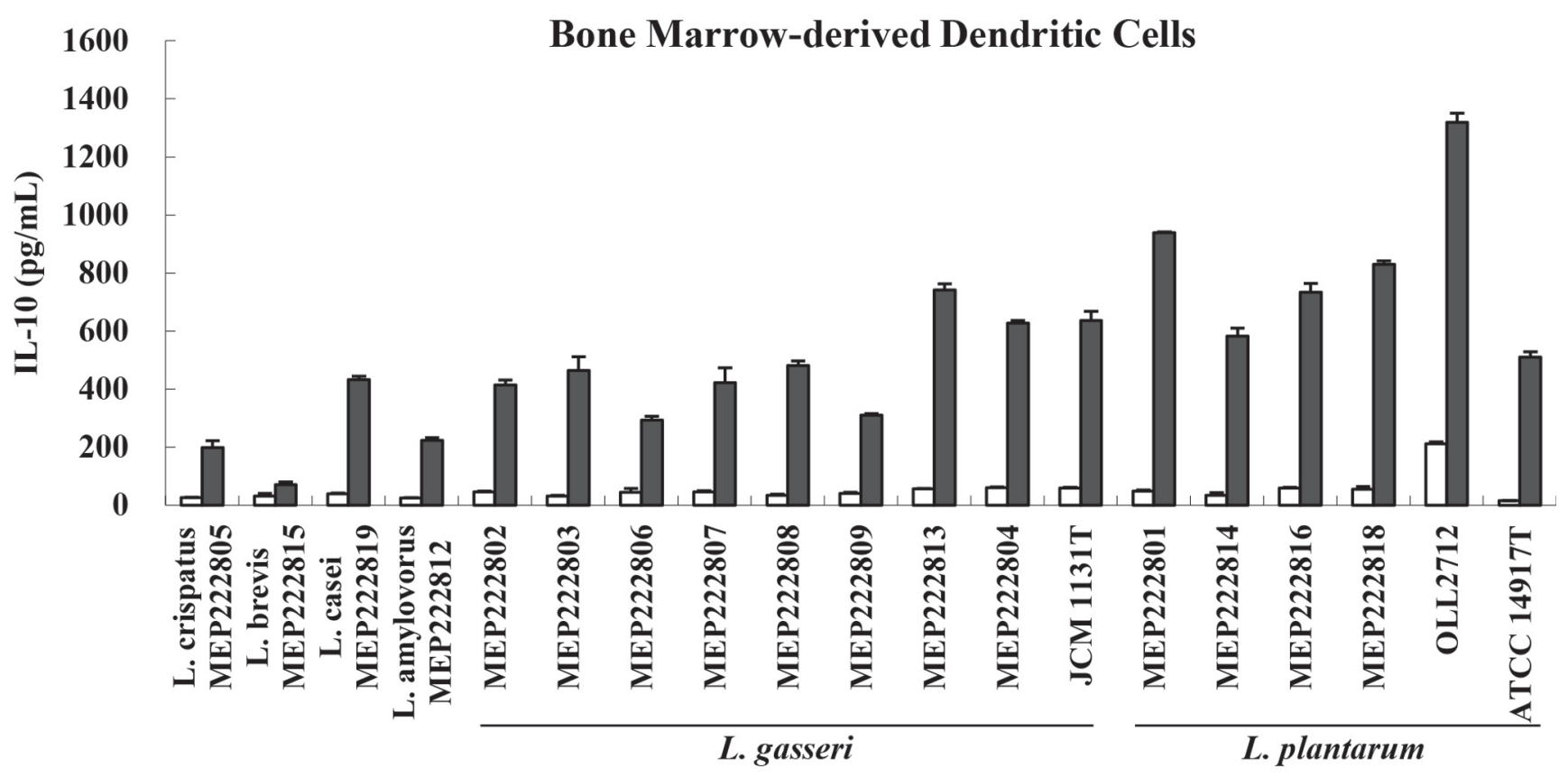

B

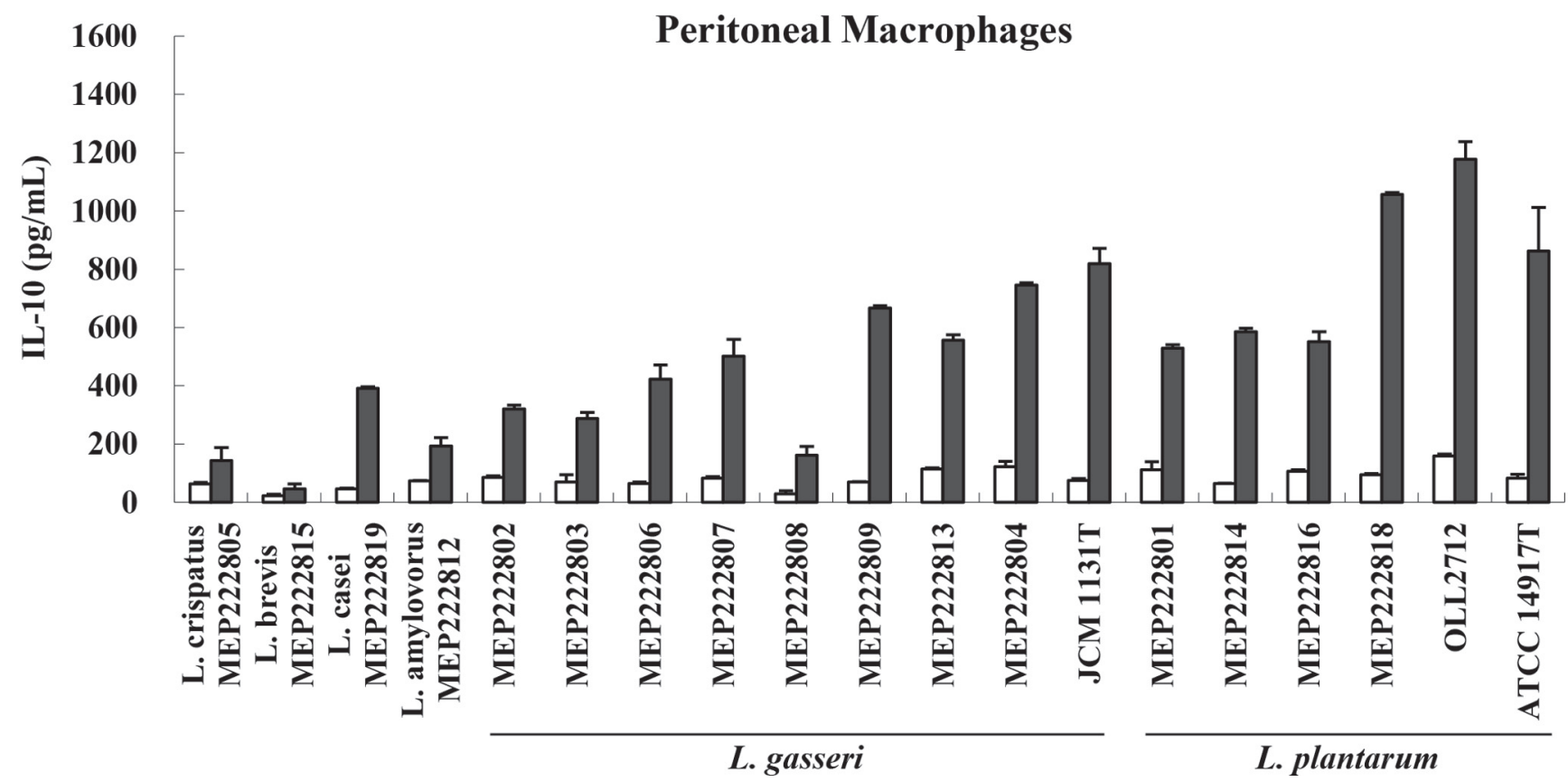

Figure 1. Screening of IL-10 secretion from bone marrow-derived dendritic cells (BMDC) and peritoneal macrophages (PM) treated with heat-killed lactic acid bacteria (LAB). Heat-killed LAB strains were used to treat BMDC (A) or thioglycolate-induced PM (B) at the indicated concentrations. After $24 \mathrm{~h}$ of stimulation, the IL-10 concentration in each culture supernatant was measured. The results are presented as means $\pm \mathrm{SE}(\mathrm{n}=4) . \mathrm{L} .=$ Lactobacillus. 
A
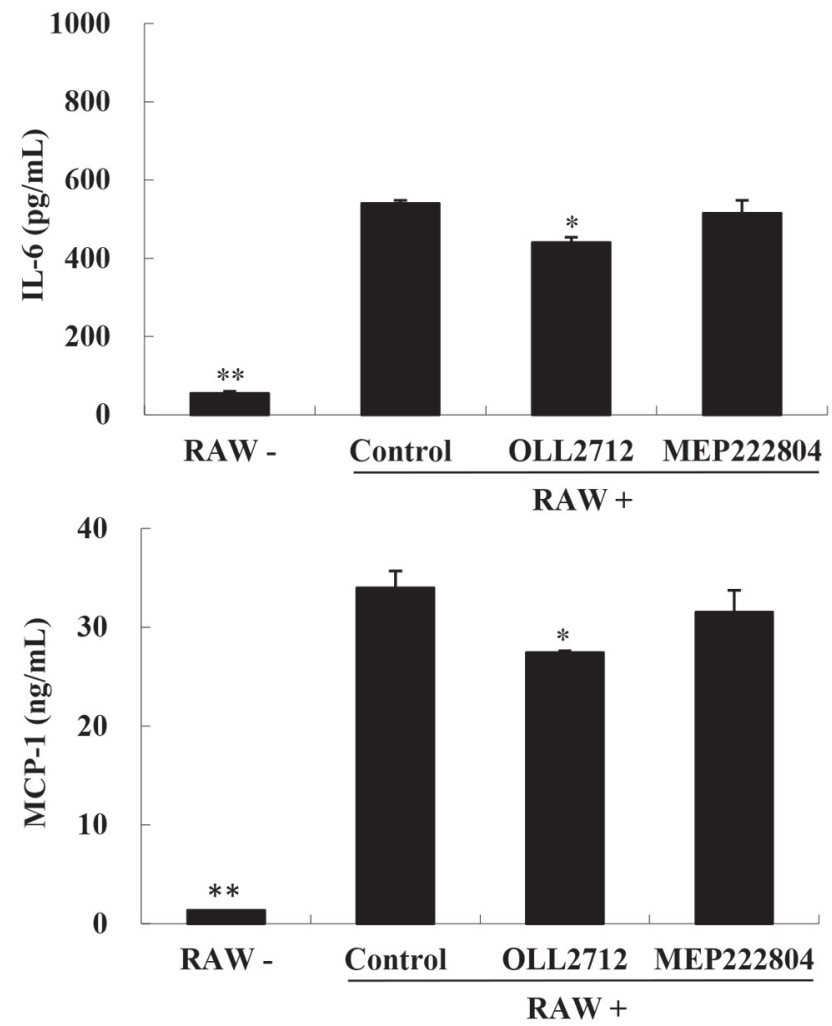

B
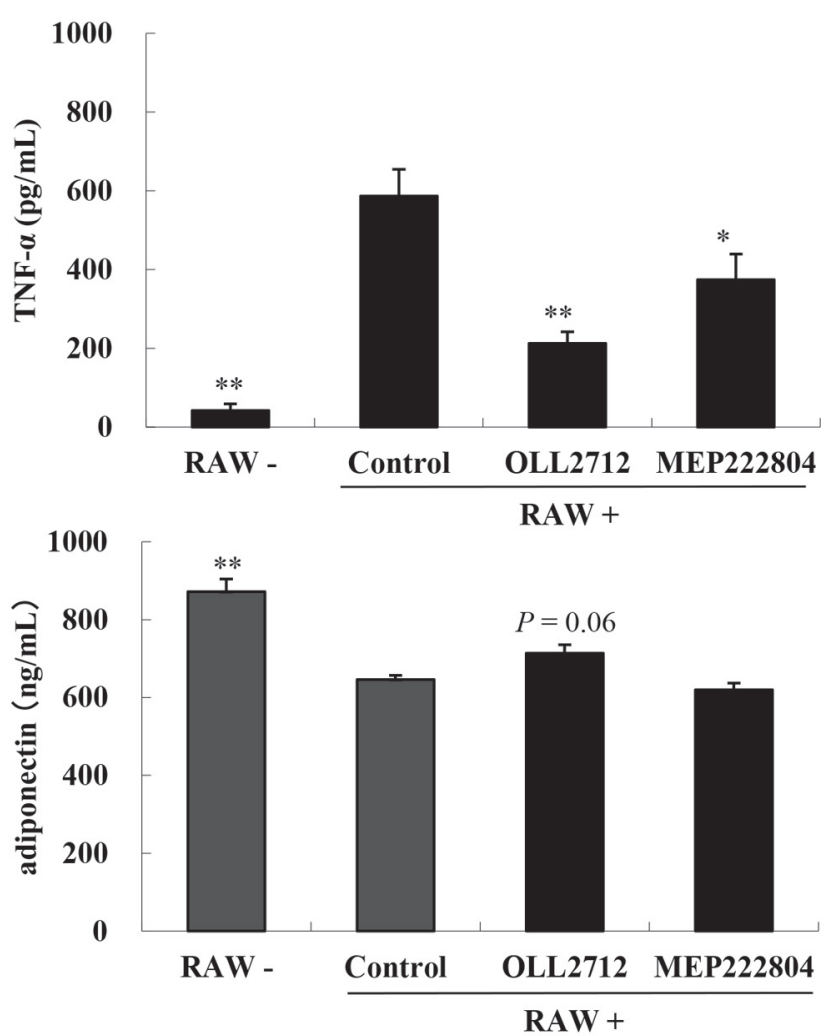

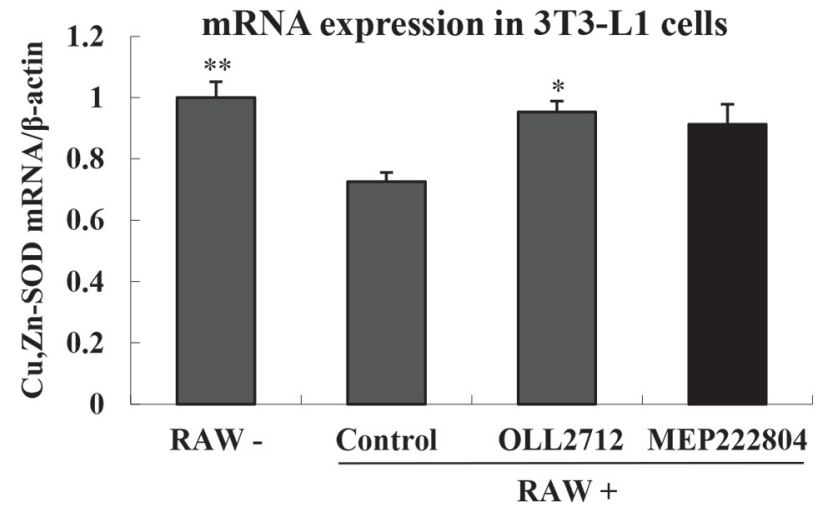

Figure 2. Anti-inflammatory effects of selected strains on co-cultured RAW 264.7 macrophages and 3T3-L1 adipocytes. RAW 264.7 cells and 3T3-L1 cells were co-cultured in Transwell plates (Corning, Acton, MA). Differentiated 3T3-L1 cells were cultured in the bottoms of the wells, whereas RAW 264.7 cells were cultured on the membranes of the Transwell inserts. The RAW 264.7 cells were then treated with the heat-killed Lactobacillus plantarum OLL2712 or Lactobacillus gasseri MEP222804 cells (10 ng/mL) for $48 \mathrm{~h}$. Untreated co-culture cells were used as the control. The concentrations of adiponectin, IL-6, tumor necrosis factor (TNF)- $\alpha$, and monocyte chemotactic protein (MCP)-1 in the supernatants of the 3T3-L1 cells (A) and the mRNA expression levels of $\mathrm{Cu}, \mathrm{Zn}$-superoxide dismutase (SOD) in 3T3-L1 cells were measured (B). The results are presented as means $\pm \mathrm{SE}(\mathrm{n}=3)$. Significant differences compared with the control were determined by Dunnett's test $\left(* P<0.05,{ }^{*} P<0.01\right)$.

with the KKAy control group, the mice treated with MEP222804 showed no difference in serum levels of triglycerides compared with the controls (Figure 3). Meanwhile, no significant difference was noted in food intake, BW, fasting blood glucose levels, serum leptin concentrations, and fasting serum total cholesterol concentrations among the 3 groups of KKAy mice (Tables 2 and 3, and Figure 3); however, the levels of each of these parameters were significantly lower in the C57BL/6J mice than in the KKAy control mice. Conversely, the serum total and high-molecular-weight (HMW; particularly active form) adiponectin concentrations were significantly higher in the C57BL/6J mice than in the KKAy control group. Neither OLL2712 nor MEP222804 administration affected these latter 2 parameters in KKAy mice (Table 3). 

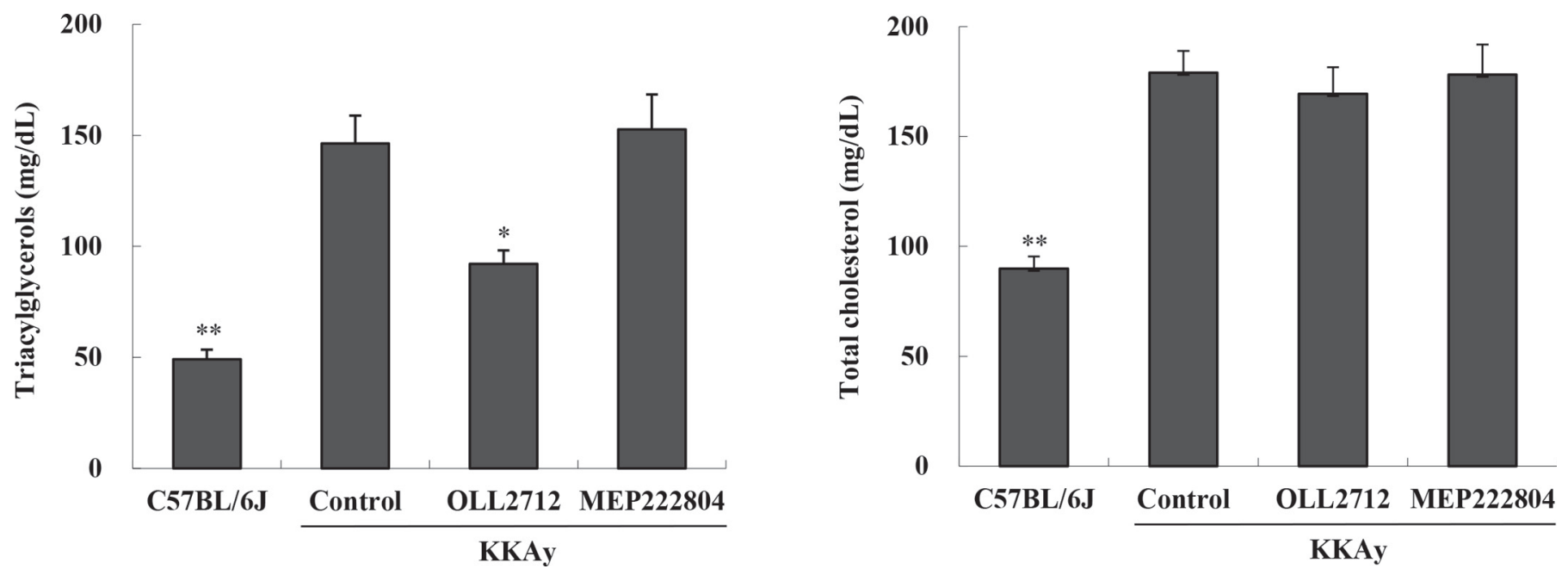

Figure 3. Serum triglyceride and total cholesterol concentration of mice. Heat-killed Lactobacillus plantarum OLL2712 or Lactobacillus gasseri MEP222804 cells were administered to KKAy mice for $3 \mathrm{wk}$. After $4 \mathrm{~h}$ of fasting, the serum concentrations of triglyceride and total cholesterol were measured. The results are presented as means $\pm \mathrm{SE}(\mathrm{n}=5$ or 6$)$. Significant differences compared with the untreated KKAy group were determined by Dunnett's test $\left({ }^{*} P<0.05,{ }^{*} P<0.01\right)$.

The serum concentrations of pro- and anti-inflammatory cytokines were also measured after the LAB administration period. No significant difference was observed in the serum concentrations of IL- $1 \beta$ and TNF- $\alpha$ between the KKAy control mice and the C57BL/6J mice (data not shown). However, the serum concentrations of IL-6, keratinocyte-derived chemokine (KC), MCP-1, and macrophage inflammatory protein- $1 \alpha$ were notably elevated, and that of IL-10 was significantly decreased, in KKAy mice compared with the C57BL/6J group (Figure 4). The administration of OLL2712 tended to decrease the serum concentration of IL-6 $(P=0.09)$ and significantly decreased the serum concentrations of $\mathrm{KC}, \mathrm{MCP}-1$, and macrophage inflammatory protein- $1 \alpha$ in KKAy mice (Figure 4). In contrast, no significant differences were seen in the serum concentrations of these cytokines between the MEP222804-treated group and the KKAy control group. Neither OLL2712 nor MEP222804 administration resulted in any significant increases in the serum concentrations of IL-10.

To assess the inflammatory response in adipose tissue, real-time PCR was used to measure mRNA levels of pro- and anti-inflammatory cytokines (IL-6, TNF- $\alpha$, MCP-1, IL-1 $\beta$, and IL-10) in visceral adipocytes. Whereas the expression levels of each of these cytokines were significantly elevated in the KKAy mice compared with the C57BL/6J mice, the expression levels were significantly reduced by treatment with either OLL2712 or MEP222804 (Figure 5). However, the levels of gene suppression were more pronounced in the OLL2712than in the MEP222804-treated group. The transcript levels of several macrophage marker genes, including F4/80 and CD68, were also significantly elevated in the visceral adipose tissue of KKAy mice compared

Table 2. Food intake, BW, and fasting serum glucose levels in KKAy mice ${ }^{1}$

\begin{tabular}{|c|c|c|c|c|}
\hline \multirow[b]{2}{*}{ Item } & \multicolumn{4}{|c|}{ KKAy mice ${ }^{2}$} \\
\hline & C57BL/6J & Control & OLL2712 & MEP222804 \\
\hline Food intake $(\mathrm{g} / 3 \mathrm{wk})$ & $76.5 \pm 1.0^{* *}$ & $109 \pm 3$ & $107 \pm 2$ & $102 \pm 3$ \\
\hline Initial BW (g) & $19.9 \pm 0.8^{* *}$ & $32.3 \pm 0.3$ & $32.3 \pm 0.6$ & $31.4 \pm 0.4$ \\
\hline Final BW (g) & $22.3 \pm 0.4^{* *}$ & $37.0 \pm 0.5$ & $37.0 \pm 0.5$ & $36.8 \pm 0.6$ \\
\hline Initial blood glucose $(\mathrm{mg} / \mathrm{dL})$ & $187 \pm 14^{* *}$ & $281 \pm 30$ & $308 \pm 19$ & $279 \pm 36$ \\
\hline Final blood glucose $(\mathrm{mg} / \mathrm{dL})$ & $182 \pm 8^{* *}$ & $337 \pm 17$ & $319 \pm 21$ & $335 \pm 31$ \\
\hline
\end{tabular}


Table 3. Serum adipokine concentrations in KKAy mice ${ }^{1}$

\begin{tabular}{|c|c|c|c|c|}
\hline \multirow[b]{2}{*}{ Item } & \multicolumn{4}{|c|}{$\mathrm{KKAy}^{2}$} \\
\hline & C57BL/6J & Control & OLL2712 & MEP222804 \\
\hline Total adiponectin $(\mu \mathrm{g} / \mathrm{mL})$ & $23.6 \pm 1.5^{* *}$ & $8.82 \pm 0.83$ & $11.0 \pm 0.8$ & $10.8 \pm 0.9$ \\
\hline $\begin{array}{l}\text { High-molecular-weight } \\
\text { adiponectin }(\mu \mathrm{g} / \mathrm{mL})\end{array}$ & $6.18 \pm 0.54^{* *}$ & $2.21 \pm 0.38$ & $3.35 \pm 0.62$ & $2.40 \pm 0.17$ \\
\hline Leptin $(\mathrm{ng} / \mathrm{mL})$ & $2.8 \pm 0.2^{* *}$ & $73.0 \pm 3.9$ & $69.4 \pm 5.4$ & $69.7 \pm 3.3$ \\
\hline \multicolumn{5}{|c|}{$\begin{array}{l}{ }^{1} \text { Values are expressed as means with SE }(n=5 \text { or } 6) \text {. Significant differences compared with the control group } \\
\text { were determined by Dunnett's test or Steel's test. }\end{array}$} \\
\hline \multicolumn{5}{|c|}{$\begin{array}{l}{ }^{2} \mathrm{C} 57 \mathrm{BL} / 6 \mathrm{~J}=\text { untreated mice used as the normal group; Control }=\text { mice administered distilled water; OLL } 2712 \\
=\text { mice administered Lactobacillus plantarum OLL2712; MEP } 222804=\text { mice administered Lactobacillus gasseri } \\
\text { MEP222804. } \\
{ }^{*} P<0.05,{ }^{* *} P<0.01 \text {. }\end{array}$} \\
\hline
\end{tabular}

with the C57BL/6J mice. Similar to the proinflammatory cytokine production levels, the F4/80 levels were significantly suppressed by treatment with OLL2712 (Figure 5). We also measured the mRNA levels of adiponectin and found these to be significantly decreased in the KKAy mice compared with the C57BL/6J mice, but unaffected by OLL2712 or MEP222804 treatment.

It has been demonstrated that exposure of visceral fat to oxidative stress results in dysregulation of adipocytokine production and increases the risk of metabolic disorders (Furukawa et al., 2004). To examine the effects of $\mathrm{LAB}$ on oxidative stress, we measured the serum levels of d-ROM, which are an indicator of oxidative stress. As depicted in Figure 6, the d-ROM values for the 3 groups of KKAy mice were significantly higher than that for the C57BL/6J mice. However, the administration of either OLL2712 or MEP222804 resulted in a significant reduction in the serum d-ROM values for the KKAy mice. These results indicate that these LAB strains exhibit a suppressive effect on oxidative stress in the mouse model (Figure 6). Conversely, no difference was noted in the serum concentrations of $8-\mathrm{OHdG}$ (a marker for oxidative DNA damage) between the experimental and control groups, indicating that LAB treatment had no effect on oxidative DNA damage.

It was previously reported that an enhancement of sympathetic nerve activity in rats following exposure to Lactobacillus paracase $i$ led to lipolysis of white adipose tissue and fat combustion (Tanida et al., 2008). We therefore analyzed the serum concentrations of adrenaline and noradrenaline, markers of sympathetic nerve activity (Yu et al., 2007). The levels of these hormones were found to be significantly higher in the untreated KKAy mice than in the C57BL/6J mice. However, mice treated with OLL2712 exhibited adrenaline and noradrenaline concentrations similar to those of the C57BL/6J group. These results suggest that OLL2712 did not accelerate sympathetic nerve activity (Figure $6)$.

\section{DISCUSSION}

Several studies have investigated the effects of LAB on metabolic disorders. Many of these were about the beneficial effects of $L$. plantarum in animal models (Takemura et al., 2010; Karlsson et al., 2011; Xie et al., 2011; Hu et al., 2013), and L. gasseri SBT2055 showed ameliorating effects on metabolic disorders in humans in a randomized controlled trial (Kadooka Y et al., 2010). However, to the best of our knowledge, no studies have screened LAB with the goal of identifying strains that could be used to treat these metabolic disorders. In the current study, we screened a panel of Lactobacillus strains and demonstrated that L. plantarum strain OLL2712 induces IL-10 production at the highest level in BMDC and PM. Meanwhile, L. gasseri MEP222804 was selected as a representative strain with moderate anti-inflammatory potential to ascertain whether strong IL-10-inducing activity is necessary for ameliorating metabolic disorders. Using a co-culture system composed of RAW 264.7 macrophages and differentiated 3T3-L1 adipocytes, we demonstrated that OLL2712 exhibited anti-inflammatory effects. We then extended these studies to examine the effects of LAB in a mouse model of obesity and T2D. Administration of heat-killed OLL2712 to KKAy mice resulted in the suppression of chronic inflammation in visceral adipose tissue and reduced serum triglyceride concentrations, indicating that treatment with this strain lowered triglyceride level via the suppression of chronic inflammation. On the other hand, administration of heatkilled MEP222804 did not ameliorate hyperlipidemia of KKAy mice, suggesting that strong IL-10-inducing activity is necessary for the potential of LAB to ameliorate metabolic disorders including hyperlipidemia.

We measured the serum IL-10 and IL-10 mRNA levels in visceral adipose tissue harvested from OLL2712treated KKAy mice and unexpectedly found no significant increase in these values compared with the 
control groups. Interleukin-10 is considered to play an important role in suppressing chronic inflammation in visceral adipose tissue and to ameliorate metabolic dis- orders (Lumeng et al., 2007; Cintra et al., 2008; Winer et al., 2009), and it was previously reported that, in individuals with metabolic disorders, IL-10 expression
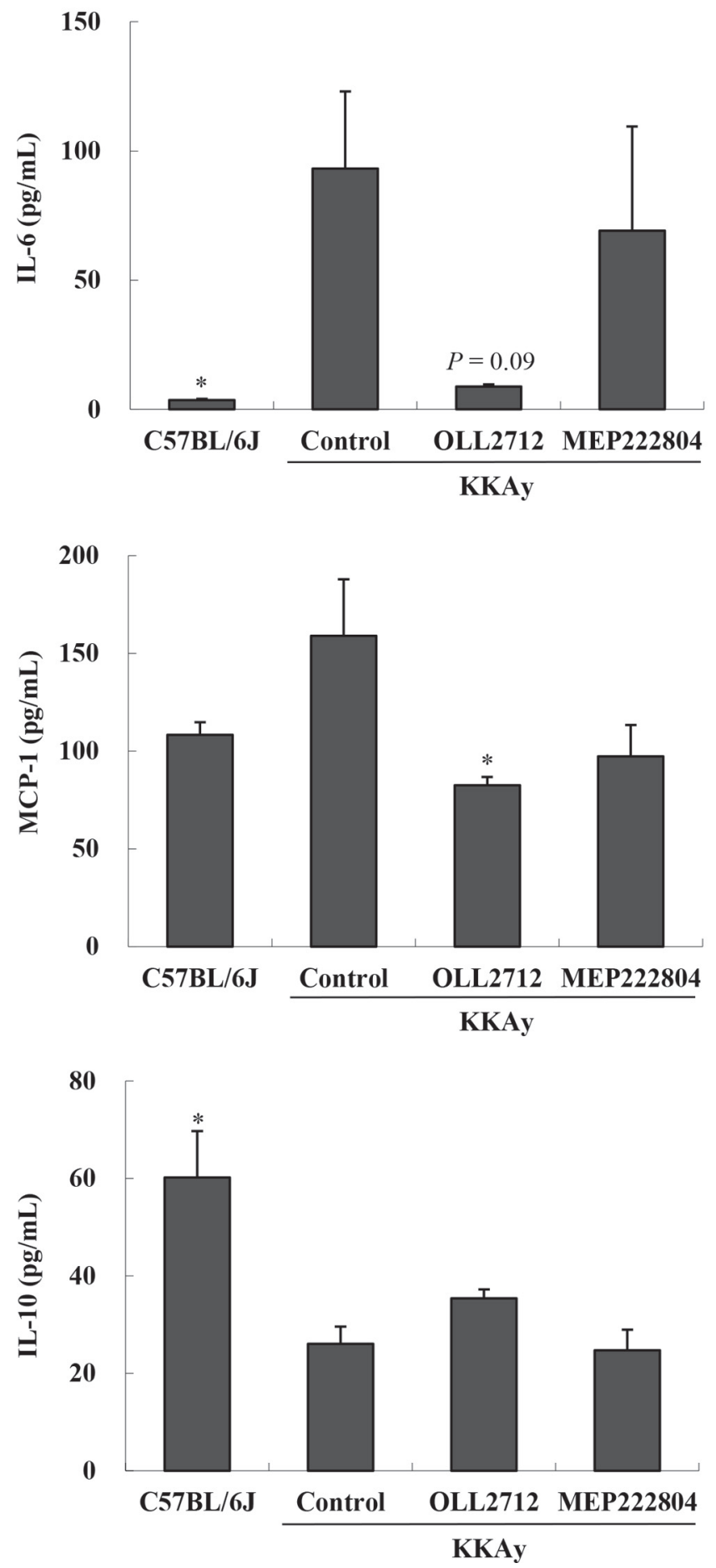
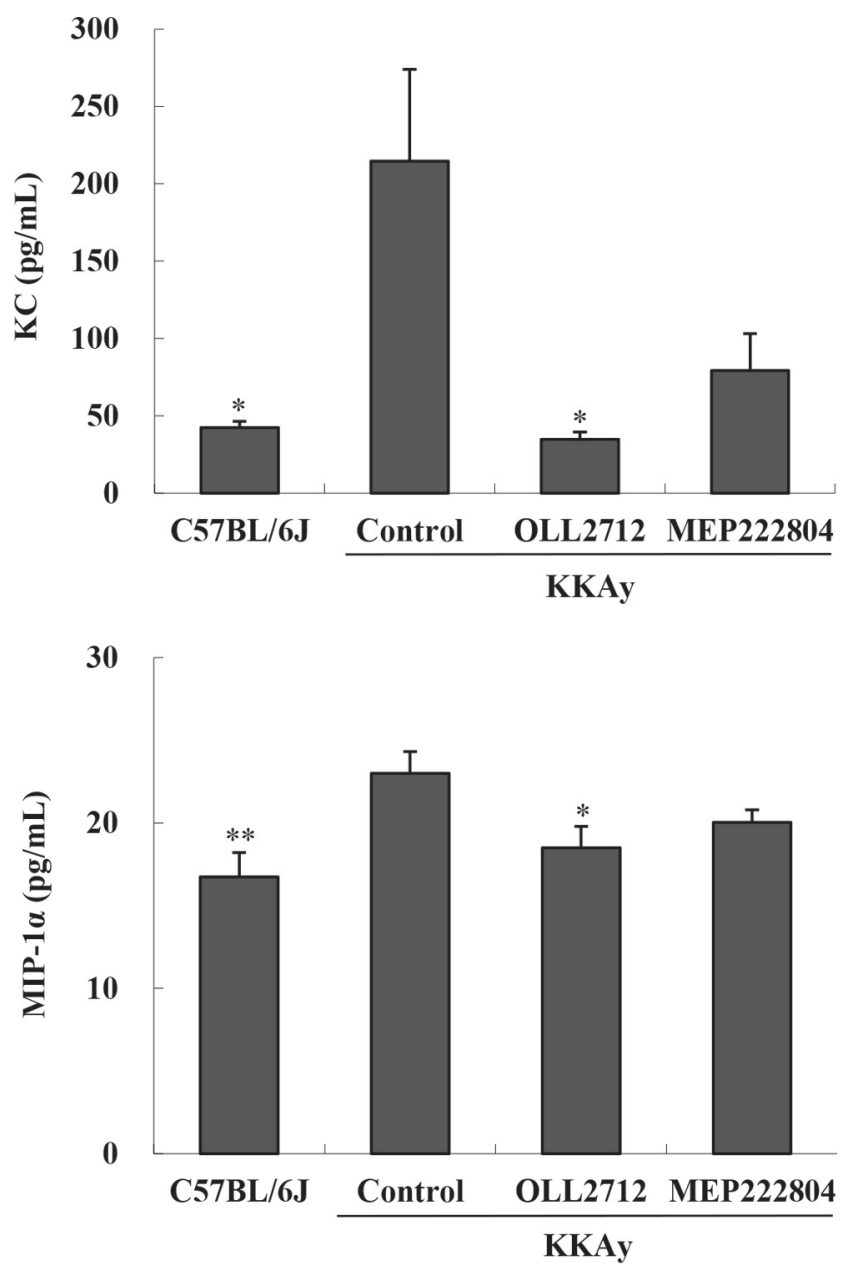

Figure 4. Serum concentrations of inflammatory cytokines in mice. KKAy mice were fed heat-killed Lactobacillus plantarum OLL2712 or Lactobacillus gasseri MEP222804 cells for $3 \mathrm{wk}$. Serum concentrations of IL-6, keratinocyte-derived chemokine (KC), monocyte chemotactic protein (MCP)-1, macrophage inflammatory protein (MIP)-1 $\alpha$, and IL-10 were then measured. The results were shown as means \pm SE $(n=5$ or 6). Significant differences compared with the untreated KKAy group were determined by Dunnett's test or Steel's test $(* P<0.05, * * P<0.01)$. 

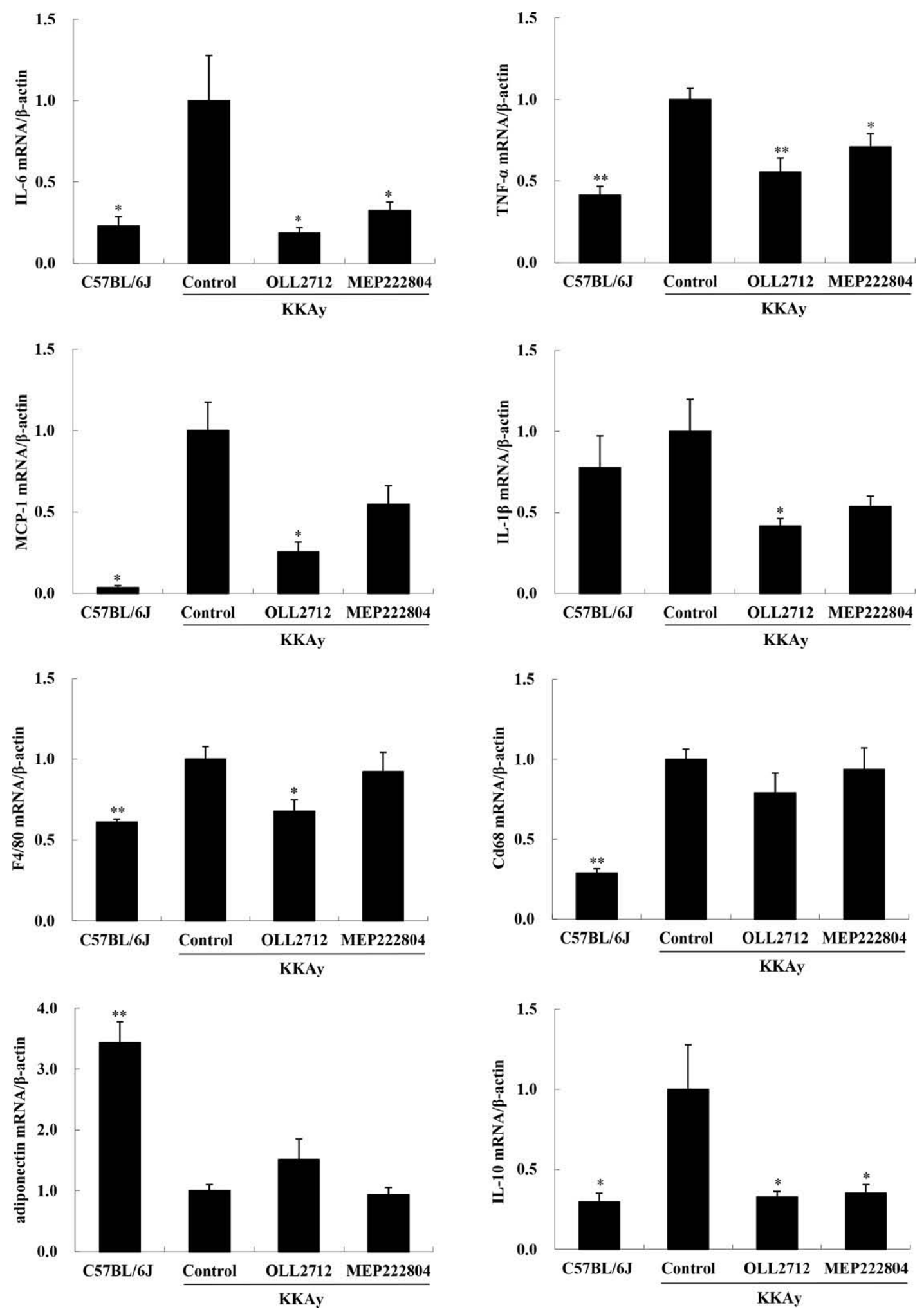

Figure 5. Expression levels of pro- and anti-inflammatory cytokines and macrophage markers in visceral adipose tissue of mice. KKAy mice were fed heat-killed Lactobacillus plantarum OLL2712 or Lactobacillus gasseri MEP222804 cells for 3 wk. Visceral adipose tissue was then harvested from the mice and RNA was extracted. Quantitative real-time PCR was used to measure transcript levels of pro- and anti-inflammatory cytokines and macrophage markers. The results are shown as means $\pm \mathrm{SE}(\mathrm{n}=5$ or 6$)$. Significant differences compared with the untreated KKAy group were determined by Dunnett's test or Steel's test $\left({ }^{*} P<0.05,{ }^{* *} P<0.01\right)$. TNF $=$ tumor necrosis factor; MCP $=$ monocyte chemotactic protein. 
was at a high level in inflamed adipose tissue as a way to combat excessive inflammation (Cintra et al., 2008; Fujisaka et al., 2009). It is considered that IL-10 is upregulated to suppress excessive inflammation in the adipose tissue and is quickly downregulated after the inflammation is suppressed completely. In addition, it is known that the half-life of mouse IL-10 is $20 \mathrm{~min}$ (Gérard et al., 1993). These reports imply that the OLL2712-mediated suppression of inflammation ultimately resulted in a reduction of IL-10 production to baseline levels by the end of the treatment regimen. In our preliminary study, we confirmed that the single dose of OLL2712 rapidly increased the mRNA expression of IL-10 in the intestine and in the adipose tissue of KKAy mice (data not shown). We consider the lack of a sustained increase in IL-10 expression in vivo to be a convincing indication that OLL2712 exerts a profound, rapid anti-inflammatory effect in the mouse model. In contrast, LPS-stimulated RAW 264.7 cells treated with either recombinant IL-10 or heat-killed OLL2712 exhibited similarly reduced levels of proinflammatory cytokines (data not shown). Based on these information, we believe that OLL2712 suppresses the secretion of proinflammatory cytokines by inducing IL10 production.

Numerous studies have investigated the correlation between proinflammatory cytokines and metabolic disorders. Loughrey et al. (2013) and Tisato et al. (2013) reported that serum IL-6 concentrations were positively correlated with the metabolic syndrome in humans. Zozuliñska et al. (1999) and Esposito et al. (2003) reported that serum IL-8 concentrations were significantly higher in T2D patients than in healthy patients. In rodents and humans, both the MCP-1 mRNA expression level in visceral adipose tissue and the MCP-1 serum concentration were found to be increased in proportion to
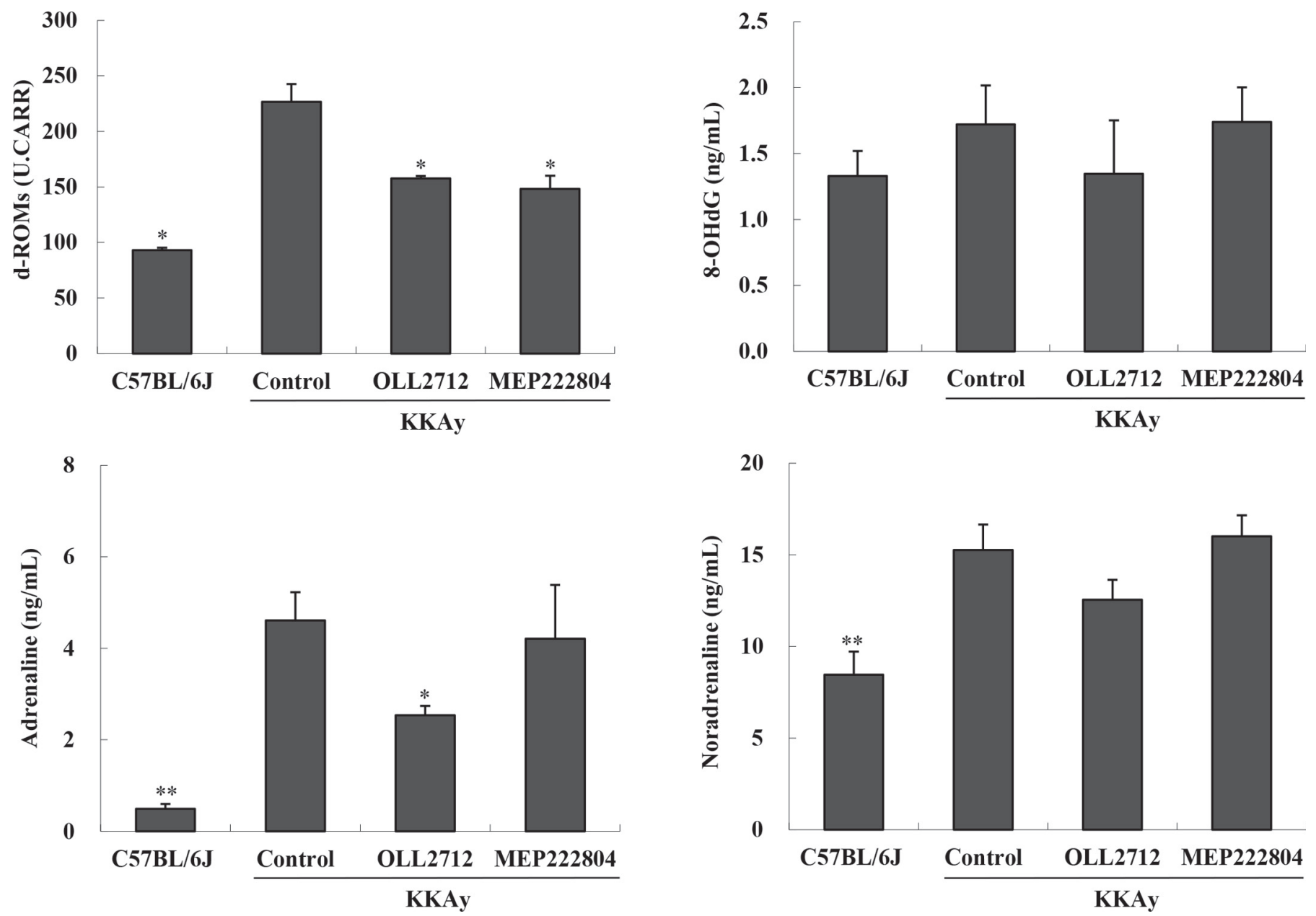

Figure 6. Serum oxidative stress values and catecholamine concentrations in mice. KKAy mice were fed heat-killed Lactobacillus plantarum OLL2712 or Lactobacillus gasseri MEP222804 cells. After $3 \mathrm{wk}$, serum levels of reactive oxygen metabolites (d-ROM) values, and 8-hydroxy2'-deoxyguanosine $(8-\mathrm{OHdG})$, adrenaline, and noradrenaline concentrations were measured. The results are depicted as means $\pm \mathrm{SE}(\mathrm{n}=5$ or 6). Significant differences compared with the untreated KKAy group were examined by Dunnett's test or Steel's test $(* P<0.05$, $* * P<0.01)$. 
the degree of obesity and were reduced by treatments for T2D (Takahashi et al., 2003; Mohanty et al., 2004; Bruun et al., 2005; Weisberg et al., 2006). Meanwhile, Larsen et al. (2007) and Osborn et al. (2008) demonstrated that blockage of IL- $1 \beta$ signaling improved glucose metabolism in randomized clinical trials and in diet-induced obesity mouse models. In the current study, we demonstrated that the oral administration of OLL2712 to KKAy mice resulted in significant decreases in the expression of IL- 6 , TNF- $\alpha$, MCP- 1 , and IL- $1 \beta$ in visceral adipose tissue and decreases in the serum concentrations of IL-6, MCP-1, and KC (Figure 5 and Figure 4), with $\mathrm{KC}$ being regarded as functional homologs of IL-8 in rodents (Huo et al., 2001). The suppression of chronic inflammation has the potential to ameliorate hyperglycemia and hyperlipidemia. Although the blood glucose concentrations were not significantly reduced in KKAy mice treated with OLL2712, an observable trend toward reduced rates of elevation of blood glucose concentrations was noted in the OLL2712 group compared with the control group $(P=0.09$, Table 2$)$. In a previous report, however, we demonstrated that OLL2712 administration significantly reduced blood glucose concentrations after insulin treatment in a dietinduced obesity model (Sakai et al., 2013). Accordingly, it is also possible that the administration of OLL2712 may be effective in ameliorating hyperglycemia.

In both human and animal studies of metabolic disorders, macrophage infiltration and activation were observed in visceral adipose tissue (Weisberg et al., 2003; Xu et al., 2003). It was also reported that adipocytes interact with infiltrating macrophages, resulting in increased production of proinflammatory cytokines (Trayhurn and Wood, 2004) and decreased production of adiponectin (Gauvreau et al., 2013; Huang et al., 2013). Consistent with these findings, we observed that 3T3-L1 adipocytes exhibited an elevated production of various proinflammatory cytokines, as well as a decreased production of adiponectin, when co-cultured with RAW 264.7 macrophages. However, the levels of these proinflammatory cytokines were significantly reduced in the co-cultured 3T3-L1 adipocytes upon treatment with OLL2712 (Figure 2). These results suggest that OLL2712 treatment may have suppressed macrophage activation in the KKAy mouse model. In addition, the reduced mRNA expression of macrophage marker gene (F4/80) observed in visceral adipose tissue samples from KKAy mice (Figure 5) indicates that OLL2712 treatment results in decreased macrophage infiltration of these tissues. The in vitro co-culture experiments also detected a trend toward a restoration of adiponectin production in the 3T3-L1 cells treated with OLL2712, compared with the untreated cells. This result also shows that the OLL2712 addition counter- acted the adverse influence mediated by the macrophage infiltration of visceral adipose tissue.

Adrenaline and noradrenaline have been shown to activate macrophages and to promote the secretion of proinflammatory cytokines (Kim et al., 2014). It has also been reported that overexpression of IL-10 in the brain reduced chronic inflammation and circulating adrenaline concentrations in rats (Yu et al., 2007). Although the serum adrenaline concentration was significantly higher in KKAy control mice than in C57BL/6J mice, administration of OLL2712 decreased the concentration in KKAy mice (Figure 6). We therefore propose that OLL2712 decreases serum adrenaline concentrations by reducing the secretion of proinflammatory cytokines. In addition, the serum adrenaline concentration positively correlates to the sympathetic nerve activity ( $\mathrm{Yu}$ et al., 2007). It is possible that enhanced sympathetic nerve activity decreases the sensitivity of $\beta_{2}$-adrenergic receptors, which would promote disorder of lipid metabolism. In contrast, stimulation of parasympathetic activities in inflammatory conditions leads to lipid homeostasis (Straznicky et al., 2008; Teshigawara et al., 2010). We speculate that the OLL2712-mediated inhibition of inflammation and normalization of adrenaline levels result in improved lipid metabolism in KKAy mice.

Increased oxidative stress in adipose tissue, due to the decreased expression of antioxidant enzymes such as CuZn-SOD, has been shown to cause an abnormal production of adipocytokines and to exacerbate metabolic disorders (Furukawa et al., 2004; Matsuda and Shimomura, 2013). The increase in reactive oxygen species production from adipose tissue also leads to increased oxidative stress in the blood, thereby affecting other organs, including the liver, skeletal muscle, and aorta. Furthermore, increased serum d-ROM levels have been linked to human metabolic disorders, including hyperlipidemia (Yamaoka-Tojo et al., 2009; Kotani and Taniguchi, 2011). It is therefore believed that an alleviation of oxidative stress in adipose tissue may cause concurrent decreases in serum reactive oxygen species concentrations and mediate improvements in obesity-associated metabolic disorders. We found that treatment with OLL2712 promoted the expression of CuZn-SOD in the coculture of RAW 264.7 and 3T3-L1 cells (Figure 2B). Furthermore, serum d-ROM values were significantly lower in mice receiving OLL2712 treatment than in the control group (Figure 6). Our findings therefore indicate that OLL2712 reduces oxidative stress in vivo. As a result, the antioxidant effect of OLL2712 might contribute to the amelioration of hyperlipidemia in KKAy mice.

In conclusion, after screening a collection of LAB strains, we demonstrated that OLL2712 exhibits profound anti-inflammatory effects in vitro. Our results 
also indicate that treatment with heat-killed OLL2712 cells ameliorates chronic inflammation and hyperlipidemia in a mouse model of obesity. In addition, it is suggested that OLL2712 may exert its effects by multiple mechanisms, including the induction of IL-10 production and suppression of proinflammatory cytokines, the inhibition of macrophage infiltration and activation in adipose tissue, and the reduction of serum levels of adrenaline and d-ROM. Although we could not prove the direct involvement of IL-10 in producing the beneficial effects of OLL2712 on KKAy mice, we demonstrated that LAB possessing strong IL-10-inducing activity have more potential to ameliorate metabolic disorders than do moderate IL-10 inducers. These findings may be an initial step toward the development of novel therapeutic strategies using LAB for the maintenance or improvement of health in individuals suffering from lifestyle-related diseases.

\section{REFERENCES}

Bruun, J. M., A. S. Lihn, S. B. Pedersen, and B. Richelsen. 2005. Monocyte chemoattractant protein-1 release is higher in visceral than subcutaneous human adipose tissue (AT): Implication of macrophages resident in the AT. J. Clin. Endocrinol. Metab. 90:2282-2289.

Cintra, D. E., J. R. Pauli, E. P. Araújo, J. C. Moraes, C. T. de Souza, M. Milanski, J. Morari, A. Gambero, M. J. Saad, and L. A. Velloso. 2008. Interleukin-10 is a protective factor against diet-induced insulin resistance in liver. J. Hepatol. 48:628-637.

Dandona, P., A. Aljada, A. Chaudhuri, P. Mohanty, and R. Garg. 2005. Metabolic syndrome: A comprehensive perspective based on interactions between obesity, diabetes, and inflammation. Circulation 111:1448-1454.

Esposito, K., F. Nappo, F. Giugliano, C. Di Palo, M. Ciotola, M. Barbieri, G. Paolisso, and D. Giugliano. 2003. Cytokine milieu tends toward inflammation in type 2 diabetes. Diabetes Care 26:1647.

Fantuzzi, G. 2005. Adipose tissue, adipokines, and inflammation. J. Allergy Clin. Immunol. 115:911-919.

Fujisaka, S., I. Usui, A. Bukhari, M. Ikutani, T. Oya, Y. Kanatami, K. Tsuneyama, Y. Nagai, K. Takatsu, M. Urakaze, and M. Kobayashi. 2009. Regulatory mechanisms for adipose tissue M1 and M2 macrophages in diet-induced obese mice. Diabetes 58:2574-2582.

Furukawa, S., T. Fujita, M. Shimabukuro, M. Iwaki, Y. Yamada, Y. Nakajima, O. Nakayama, M. Makishima, M. Matsuda, and I. Shimomura. 2004. Increased oxidative stress in obesity and its impact on metabolic syndrome. J. Clin. Invest. 114:1752-1761.

Gauvreau, D., A. Gupta, A. Fisette, F. Q. Tom, and K. Cianflone. 2013. Deficiency of C5L2 increases macrophage infiltration and alters adipose tissue function in mice. PLoS ONE 8:e60795.

Gérard, C., C. Bruyns, A. Marchant, D. Abramowicz, P. Vandenabeele, A. Delvaux, W. Fiers, M. Goldman, and T. Velu. 1993. Interleukin 10 reduces the release of tumor necrosis factor and prevents lethality in experimental endotoxemia. J. Exp. Med. 177:547-550.

Howard, M., and A. O'Garra. 1992. Biological properties of interleukin 10. Immunol. Today 13:198-200.

Hu, X., T. Wang, W. Li, F. Jin, and L. Wang. 2013. Effects of NS Lactobacillus strains on lipid metabolism of rats fed a high-cholesterol diet. Lipids Health Dis. 12:67.

Huang, Z. H., B. Manickam, V. Ryvkin, X. J. Zhou, G. Fantuzzi, T. Mazzone, and S. Sam. 2013. PCOS is associated with increased CD11c expression and crown-like structures in adipose tissue and increased central abdominal fat depots independent of obesity. J. Clin. Endocrinol. Metab. 98:E17-E24.
Huo, Y., C. Weber, S. B. Forlow, M. Sperandio, J. Thatte, M. Mack, S. Jung, D. R. Littman, and K. Ley. 2001. The chemokine KC, but not monocyte chemoattractant protein-1, triggers monocyte arrest on early atherosclerotic endothelium. J. Clin. Invest. 108:13071314.

Kadooka, Y., M. Sato, K. Imaizumi, A. Ogawa, K. Ikuyama, Y. Akai, M. Okano, M. Kagoshima, and T. Tsuchida. 2010. Regulation of abdominal adiposity by probiotics (Lactobacillus gasseri SBT2055) in adults with obese tendencies in a randomized controlled trial. Eur. J. Clin. Nutr. 64:636-643.

Karlsson, C. L., G. Molin, F. Fåk, M. L. Johansson Hagslätt, M. Jakesevic, Å. Håkansson, B. Jeppsson, B. Weström, and S. Ahrné. 2011. Effects on weight gain and gut microbiota in rats given bacterial supplements and a high-energy-dense diet from fetal life through to 6 months of age. Br. J. Nutr. 106:887-895.

Kawashima, T., A. Kosaka, H. Yan, Z. Guo, R. Uchiyama, R. Fukui, D. Kaneko, Y. Kumagai, D. J. You, J. Carreras, S. Uematsu, M. H. Jang, O. Takeuchi, T. Kaisho, S. Akira, K. Miyake, H. Tsutsui, T. Saito, I. Nishimura, and N. M. Tsuji. 2013. Double-stranded RNA of intestinal commensal but not pathogenic bacteria triggers production of protective interferon- $\beta$. Immunity 38:1187-1197.

Kim, M. H., F. Gorouhi, S. Ramirez, J. L. Granick, B. A. Byrne, A. M. Soulika, S. I. Simon, and R. R. Isseroff. 2014. Catecholamine stress alters neutrophil trafficking and impairs wound healing by 32-adrenergic receptor-mediated upregulation of IL-6. J. Invest. Dermatol. 134:809-817.

Kotani, K., and N. Taniguchi. 2011. The association between reactive oxygen metabolites and metabolic syndrome in asymptomatic Japanese men. J. Clin. Med. Res. 3:247-251.

Larsen, C. M., M. Faulenbach, A. Vaag, A. Vølund, J. A. Ehses, B. Seifert, T. Mandrup-Poulsen, and M. Y. Donath. 2007. Interleukin-1-receptor antagonist in type 2 diabetes mellitus. N. Engl. J. Med. 356:1517-1526.

Loughrey, B. V., A. McGinty, I. S. Young, D. R. McCance, and L. A. Powell. 2013. Increased circulating CC chemokine levels in the metabolic syndrome are reduced by low-dose atorvastatin treatment: Evidence from a randomized controlled trial. Clin. Endocrinol. (Oxf.) 79:800-806.

Lumeng, C. N., J. L. Bodzin, and A. R. Saltiel. 2007. Obesity induces a phenotypic switch in adipose tissue macrophage polarization. J. Clin. Invest. 117:175-184.

Matsuda, M., and I. Shimomura. 2013. Increased oxidative stress in obesity: Implications for metabolic syndrome, diabetes, hypertension, dyslipidemia, atherosclerosis, and cancer. Obes. Res. Clin. Pract. 7:e330-e341.

Mohanty, P., A. Aljada, H. Ghanim, D. Hofmeyer, D. Tripathy, T. Syed, W. Al-Haddad, S. Dhindsa, and P. Dandona. 2004. Evidence for a potent antiinflammatory effect of rosiglitazone. J. Clin. Endocrinol. Metab. 89:2728-2735.

Naito, E., Y. Yoshida, K. Makino, Y. Kounoshi, S. Kunihiro, R. Takahashi, T. Matsuzaki, K. Miyazaki, and F. Ishikawa. 2011. Beneficial effect of oral administration of Lactobacillus casei strain Shirota on insulin resistance in diet-induced obesity mice. J. Appl. Microbiol. 110:650-657.

Osborn, O., S. E. Brownell, M. Sanchez-Alavez, D. Salomon, H. Gram, and T. Bartfai. 2008. Treatment with an interleukin 1 beta antibody improves glycemic control in diet-induced obesity. Cytokine 44:141-148.

Parvez, S., K. A. Malik, S. Ah Kang, and H. Y. Kim. 2006. Probiotics and their fermented food products are beneficial for health. J. Appl. Microbiol. 100:1171-1185.

Sakai, T., T. Taki, A. Nakamoto, E. Shuto, R. Tsutsumi, T. Toshimitsu, S. Makino, and S. Ikegami. 2013. Lactobacillus plantarum OLL2712 regulates glucose metabolism in C57BL/6 mice fed a high-fat diet. J. Nutr. Sci. Vitaminol. (Tokyo) 59:144-147.

Sashihara, T., N. Sueki, and S. Ikegami. 2006. An analysis of the effectiveness of heat-killed lactic acid bacteria in alleviating allergic diseases. J. Dairy Sci. 89:2846-2855.

Shoelson, S. E., L. Herrero, and A. Naaz. 2007. Obesity, inflammation, and insulin resistance. Gastroenterology 132:2169-2180. 
Straznicky, N. E., N. Eikelis, E. A. Lambert, and M. D. Esler. 2008 Mediators of sympathetic activation in metabolic syndrome obesity. Curr. Hypertens. Rep. 10:440-447.

Suganami, T., J. Nishida, and Y. Ogawa. 2005. A paracrine loop between adipocytes and macrophages aggravates inflammatory changes: Role of free fatty acids and tumor necrosis factor alpha. Arterioscler. Thromb. Vasc. Biol. 25:2062-2068.

Takahashi, K., S. Mizuarai, H. Araki, S. Mashiko, A. Ishihara, A. Kanatani, H. Itadani, and H. Kotani. 2003. Adiposity elevates plasma MCP-1 levels leading to the increased CD11b-positive monocytes in mice. J. Biol. Chem. 278:46654-46660.

Takemura, N., T. Okubo, and K. Sonoyama. 2010. Lactobacillus plantarum strain No. 14 reduces adipocyte size in mice fed high-fat diet. Exp. Biol. Med. (Maywood) 235:849-856.

Tanida, M., J. Shen, K. Maeda, Y. Horii, T. Yamano, Y. Fukushima, and K. Nagai. 2008. High-fat diet-induced obesity is attenuated by probiotic strain Lactobacillus paracasei ST11 (NCC2461) in rats. Obes. Res. Clin. Pract. 2:I-II.

Teshigawara, K., T. Hosaka, M. Yamaguchi, E. Terada, Y. Kisyuku, K. Fukunaga, Y. Hirata, B. Jambaldorj, N. Harada, T. Sakai, and Y. Nakaya. 2010. Long-term treatment with hyperbaric air improves hyperlipidemia of db/db mice. J. Med. Invest. 57:224-231.

Tisato, V., B. Toffoli, L. Monasta, S. Bernardi, R. Candido, G. Zauli and P. Secchiero. 2013. Patients affected by metabolic syndrome show decreased levels of circulating platelet derived growth factor (PDGF)-BB. Clin. Nutr. 32:259-264.

Trayhurn, P., and I. S. Wood. 2004. Adipokines: Inflammation and the pleiotropic role of white adipose tissue. Br. J. Nutr. 92:347-355.

van Exel, E., J. Gussekloo, A. J. de Craen, M. Frölich, A. Bootsma-Van Der Wiel, and R. G. Westendorp. 2002. Low production capacity of interleukin-10 associates with the metabolic syndrome and type 2 diabetes: the Leiden 85-Plus Study. Diabetes 51:1088-1092.
Weisberg, S. P., D. Hunter, R. Huber, J. Lemieux, S. Slaymaker, K. Vaddi, I. Charo, R. L. Leibel, and A. W. Ferrante Jr.. 2006. CCR2 modulates inflammatory and metabolic effects of high-fat feeding. J. Clin. Invest. 116:115-124.

Weisberg, S. P., D. McCann, M. Desai, M. Rosenbaum, R. Leibel, and A. W. Ferrante Jr.. 2003. Obesity is associated with macrophage accumulation in adipose tissue. J. Clin. Invest. 112:1796-1808.

Winer, S., Y. Chan, G. Paltser, D. Truong, H. Tsui, J. Bahrami, R. Dorfman, Y. Wang, J. Zielenski, F. Mastronardi, Y. Maezawa, D. J. Drucker, E. Engleman, D. Winer, and H. M. Dosch. 2009. Normalization of obesity-associated insulin resistance through immunotherapy. Nat. Med. 15:921-929.

Xie, N., Y. Cui, Y. N. Yin, X. Zhao, J. W. Yang, Z. G. Wang, N. Fu, Y. Tang, X. H. Wang, X. W. Liu, C. L. Wang, and F. G. Lu. 2011. Effects of two Lactobacillus strains on lipid metabolism and intestinal microflora in rats fed a high-cholesterol diet. BMC Complement. Altern. Med. 11:53.

Xu, H., G. T. Barnes, Q. Yang, G. Tan, D. Yang, C. J. Chou, J. Sole, A. Nichols, J. S. Ross, L. A. Tartaglia, and H. Chen. 2003. Chronic inflammation in fat plays a crucial role in the development of obesity-related insulin resistance. J. Clin. Invest. 112:1821-1830.

Yamaoka-Tojo, M., T. Tojo, R. Kosugi, Y. Hatakeyama, Y. Yoshida, Y. Machida, N. Aoyama, T. Masuda, and T. Izumi. 2009. Effects of ezetimibe add-on therapy for high-risk patients with dyslipidemia. Lipids Health Dis. 8:41.

Yu, Y., Z. H. Zhang, S. G. Wei, Y. Chu, R. M. Weiss, D. D. Heistad, and R. B. Felder. 2007. Central gene transfer of interleukin-10 reduces hypothalamic inflammation and evidence of heart failure in rats after myocardial infarction. Circ. Res. 101:304-312.

Zozuliñska, D., A. Majchrza, M. Sobieska, K. Wiktorowicz, and B. Wierusz-Wysocka. 1999. Serum interleukin-8 level is increased in diabetic patients. Diabetologia 42:117-118. 